\title{
Annick Bouillaguet, Proust lecteur de Balzac et de Flaubert. L'imitation cryptée
}

\section{Emanuele Kanceff}

\section{(2) OpenEdition}

1 Journals

\section{Edizione digitale}

URL: https://journals.openedition.org/studifrancesi/39732

DOI: 10.4000/studifrancesi.39732

ISSN: 2421-5856

\section{Editore}

Rosenberg \& Sellier

\section{Edizione cartacea}

Data di pubblicazione: 1 décembre 2004

Paginazione: 407

ISSN: 0039-2944

\section{Notizia bibliografica digitale}

Emanuele Kanceff, «Annick Bouillaguet, Proust lecteur de Balzac et de Flaubert. L'imitation cryptée», Studi Francesi [Online], 143 (XLVIII | II) | 2004, online dal 30 novembre 2015, consultato il 19 mai 2021. URL: http://journals.openedition.org/studifrancesi/39732 ; DOI: https://doi.org/10.4000/studifrancesi. 39732

Questo documento è stato generato automaticamente il 19 mai 2021.

\section{(c) $($ ) $\odot$ EY}

Studi Francesi è distribuita con Licenza Creative Commons Attribuzione - Non commerciale - Non opere derivate 4.0 Internazionale. 


\title{
Annick Bouillaguet, Proust lecteur de Balzac et de Flaubert. L'imitation cryptée
}

\author{
Emanuele Kanceff
}

\section{NOTIZIA}

ANNick BoullLaguet, Proust lecteur de Balzac et de Flaubert. L'imitation cryptée, Préface de Brian G. Rogers, Paris, Honoré Champion Editeur, 2000 («Littérature de notre siècle», 15), pp. 238.

1 La domanda che Charles Nodier si faceva nell'His-toire du roi de Bohème, «Oserais-je vous demander quel livre n'est pas pastiche?» si trova al centro della scrittura proustiana e della sua estetica. Gli episodi e le situazioni di intertestualità sono correnti nella Recherche, tutti i personaggi del romanzo si appropriano, in un modo o nell'altro, di un linguaggio che non è il loro, ma che finisce per calzare perfettamente sulla loro persona. Il libro stesso è variegato di frammenti di altre opere, oggetti rubati che finiscono per cementarsi assieme l'un l'altro in un prodotto coerente. Le riflessioni stesse del narratore sono una pista interessante e chiarificatrice al proposito.

2 Come può il lettore riconoscere l'origine di tutte queste citazioni proustiane? Alcune rimangono indubbiamente misteriose e indecifrabili; altre, più moderne e correnti, più evidenti per i contemporanei, sono diventate soggetto di ricerca che finiscono per cementarsi assieme l'un l'altro in un prodotto coerente. Le riflessioni stesse del narratore sono una pista interessante e chiarificatrice al proposito. Tra questi possibili itinerari, l'A. ha scelto Balzac e Flaubert.

3 L'imitazione, in Proust, consiste sia nel sovrapporre sia nell'alternare due strati di scrittura, la sua che ricopre e quella di un altro autore che proviene da un testo preesistente. Questo atto ha, in lui, la particolarità di integrarsi in un processo di creazione letteraria più generale e perfettamente naturale. L'esame delle brutte copie 
dei manoscritti della Recherche mostra che la disposizione del testo nella pagina non obbedisce alle necessità di una scrittura orientata da sinistra a destra, ma segue un ordine che è allo stesso tempo orizzontale e verticale, con un testo base che si sviluppa in modo lineare e per aggiunte e punti di inserimento. Questo modo di scrivere traduce e testimonia una modalità di composizione basata su frammenti aggiunti che informano la materia presente fin dall'inizio. In tale condizione il prestito diventa la forma base della riscrittura, in base a regole che l'A. svela in modo perspicace: un nome per un altro, i nomi cancellati, le sostituzioni, le enumerazioni, le regole della descrizione, le immagini e la loro giustapposizione, la ripresa di vecchi temi, la riesumazione dei personaggi - tratti da Balzac, dal mondo flaubertiano - la riesumazione degli usi e delle idee, il trattamento della storia.

4 Quasi sempre criptato, il pastiche integrato nella scrittura è per Proust un modo per esprimere il senso della storia non narrata, di una storia i cui avvenimenti non sono generalmente evocati che per l'influsso che esercitano sulle coscienze e sull'inconscio. Questo modo di comprendere le parole degli altri che è il pastiche proustiano è anche uno sforzo di traduzione originale della parola dimenticata, che è utilizzabile a condizione di essere tradotta in un linguaggio universale che ne faccia un'acquisizione perpetua. 